\title{
Dermoid Cyst of the Limbus in GOLDENHAR Syndrome (Kyste Dermoide Du Limbe Dans Le Cadre Du Syndrome De GOLDENHAR) \\ H. Atidi ${ }^{1 *}$, S.Boutgayout ${ }^{1}$, D.Jaafari ${ }^{1}$, N.Inzale ${ }^{1}$, S.Belghmaidi ${ }^{1}$, .Hajji $^{1}$, A.Moutaouakil ${ }^{1}$
}

${ }^{1}$ Ophthalmology Department, Mohammed VI University Hospital - Marrakech, Morocco

DOI: $10.36347 /$ sasjm.2021.v07i05.007

| Received: 19.03.2021 | Accepted: 24.04.2021 | Published: 26.05.2021

*Corresponding author: H. Atidi

Copyright (C) 2021 The Author(s): This is an open-access article distributed under the terms of the Creative Commons Attribution 4.0 International License (CC BY-NC 4.0) which permits unrestricted use, distribution, and reproduction in any medium for non-commercial use provided the original author and source are credited.

We report the case of a 4-year-old girl with a history of atresia of the esophagus, the ophthalmological examination found in the left eye an impregnable refraction, a normal eye tone, a dermid cyst of the temporal limbus infiltrating the cornea with a symblepharon (figure 1 and 2), the lens is transparent and the fundus is normal.

In the right eye, we find a temporal symblepharon (figure 3), an anterior segment and fundus are normal.

General examination finds bilateral preauricular appendages and in the neck (Figure 4). A UBM reveals an echogenic temporal limbic process, poorly limited with cystic appearance that invades the underlying structures: cornea and sclera (Figure 5). She was treated by excision with an amniotic membrane.

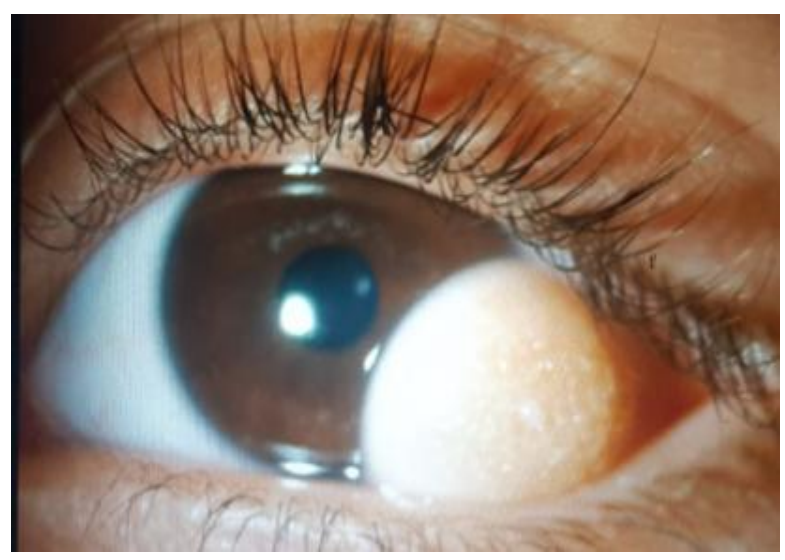

Fig-1

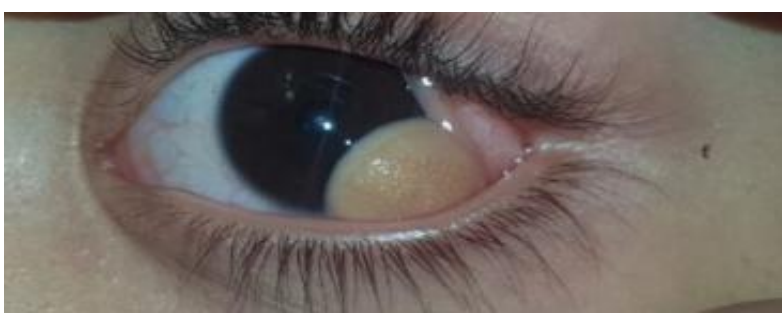

Fig-2

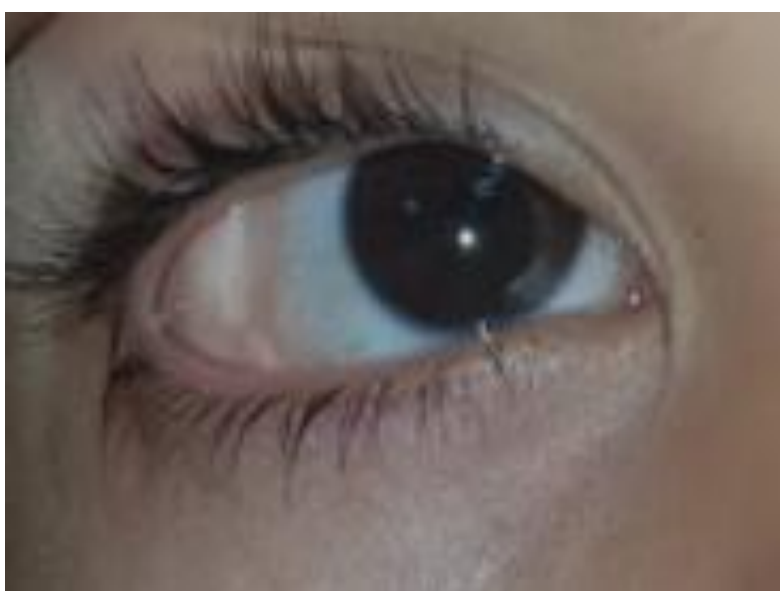

Fig-3
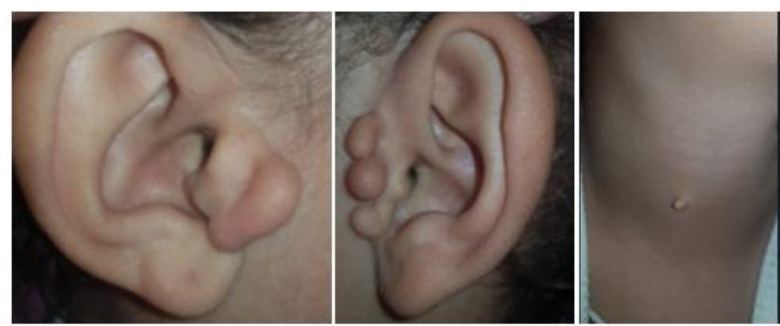

Fig-4 